ERDC/CRREL TN-21-1

September 2021

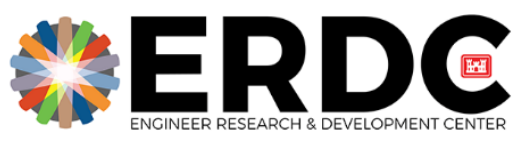

\title{
Shear and Tensile Delamination of Ice from Surfaces: The Ice Adhesion Peel Test (IAPT)
}

By Alexis R. Lovell, Garrett R. Hoch, Christopher J. Donnelly, Jordan M. Hodge, Robert B. Haehnel, and Emily Asenath-Smith

PURPOSE: For decades, researchers have sought to understand the adhesion of ice to surfaces so that low-cost ice mitigation strategies can be developed. Presently, the field of ice adhesion is still without formal standards for performing ice adhesion tests. The U.S. Army Corps Engineers' Research and Development Center's Cold Regions Research and Engineering Laboratory (ERDCCRREL) has a longstanding history as an independent third party for ice adhesion testing services. Most notably, CRREL's Zero-Degree Cone Test (ZDCT) has been an industry favorite for more than 30 years. Despite its wide acceptance, the ZDCT contains some shortcomings, namely that freshwater ice is formed on the surface of interest within the confines of an annular gap. To address this limitation, CRREL developed and uses the Ice Adhesion Peel Test (IAPT) for testing ice adhesion. This test employs an open planar substrate from which the ice can be removed under either tensile or shear loading, thereby allowing ice to be grown directly on the target substrate without the use of molds. The IAPT configuration is therefore amenable to different ice types and geometries and will provide utility to research studies that aim to develop surface treatments to mitigate ice in a wide range of environments. This report describes the IAPT and its use for characterizing the ice adhesion properties of materials.

BACKGROUND: Ice accumulation on surfaces poses detrimental impacts to the safety and success of systems and operations worldwide, inhibiting energy production and transmission, severing communications, and halting transportation, for example. Therefore, understanding how to treat or prevent the accumulation of ice is a highly active field of study.

Ice mitigation research follows two approaches, active or passive. An active approach aims to diminish ice accretion by way of energy input, such as through electrical and thermal heaters or by supplying air to pneumatic boots. Even the process of ice removal carried out by military service members (with mallets and ice mauls) is an active process. Conversely, a passive approach to controlling ice accumulation involves engineering surface properties, often via coatings, to prevent ice growth or to facilitate ice shedding.

While government agencies are highly invested in both realms of research, there is yet to be an established ASTM standard for assessing coating materials for passive ice mitigation strategies. While Hakimian, Nazifi, and Ghasemi (2020) and others have made efforts to standardize approaches to ice adhesion testing, there is not yet agreement on a single approach. As a result, an expanse of unique testing configurations has been developed across the field, all of which employ a range of ice types and loading modes. Consequently, each testing configuration yields vastly different adhesion values even on identical specimens. This reality poses significant challenges to decision-makers aiming to compare results and transition technologies to real settings. 
For the past 30 years, CRREL has been an active member of the ice adhesion community, providing ice adhesion testing services as an independent third-party verification for companies developing coatings for passive means of ice mitigation. The most widely known test, the ZDCT, consists of a shear load applied to a confined ice-substrate assembly (Haehnel and Mulherin 1998). In addition, CRREL developed the lap shear test for ice adhesion (Ferrick et al. 2006a, 2006b). However, both tests have some shortcomings. Firstly, ice is adhered to the test surface using molds, which impart strain in the ice, necessitating a 24-hour rest period before testing. Secondly, the confined nature of the interfaces disqualifies these tests from use with different ice types (e.g., impact ice or saline spray ice). To fill this gap, CRREL developed the IAPT, which is the focus of this report.

In short, the IAPT is a versatile test method that uses a planar substrate with an unconfined ice interface. The adhered ice is most commonly freshwater columnar ice, but the ice can also be formed by droplet deposition as in saline spray ice and accretion or impact ice. The adhered ice can be delaminated by shear sliding along the substrate surface or by tensile peeling of the ice away from the substate. The test substrate can be of variable size or aspect ratio, up to $120 \mathrm{~mm}^{1}$ on each side.

This report describes the test configuration, and its versatility, and provides data on the adhesion of freshwater columnar ice to a selection of commercially available coatings that were tested in both shear and tensile modes. These values are provided as reference information for validation and comparison of new coatings that are under development.

\section{METHODS}

Ice adhesion testing. The IAPT can be carried out in either tensile or shear modes in a standard mechanical load frame (Figure 1). In the tensile mode, the ice is lifted away from the substrate; in the shear mode, the ice is pushed off the substrate along its surface. In general, tests can be conducted under strain- or load-driven conditions. In the tests reported here, strain-driven conditions were employed with a load head displacement rate of $0.6 \mathrm{~mm} / \mathrm{min}$. This value is typically used for ice adhesion tests in both modes; however, this rate can be modified for different scenarios as desired. During a test, the maximum force and displacement are recorded as a function of time, and the specimen can be monitored with live video during the test. Following testing, the apparent ice adhesion strength $\left(\mathrm{IAS}_{\mathrm{app}}\right)$ can be calculated according to equation (1):

$$
\mathrm{IAS}_{\mathrm{app}}=\frac{F_{\mathrm{max}}}{\text { Area }}
$$

The IAPT set up is amenable to a range of substrate sizes, ranging from 20 to $120 \mathrm{~mm}$ along one side (Figure 2). All tests reported herein used a $30 \times 40 \mathrm{~mm}$ substrate and thus had a nominal contact area of $1200 \mathrm{~mm}^{2}$, the value used for the $\mathrm{IAS}_{\text {app }}$ calculation. A minimum of five replicate specimens are targeted for each condition.

\footnotetext{
${ }^{1}$ For a full list of the spelled-out forms of the units of measure used in this document, please refer to U.S. Government Publishing Office Style Manual, 31st ed. (Washington, DC: U.S Government Publishing Office, 2016), 248-252, https://www.govinfo.gov/content/pkg/GPO-STYLEMANUAL-2016/pdf/GPO-STYLEMANUAL2016.pdf.
} 


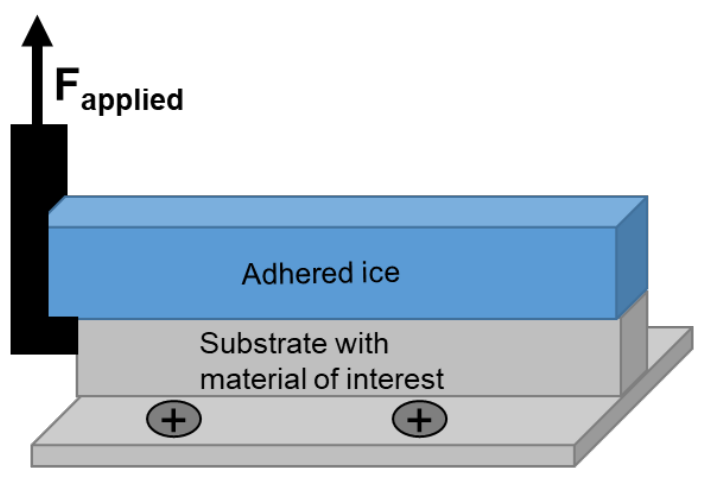

b)

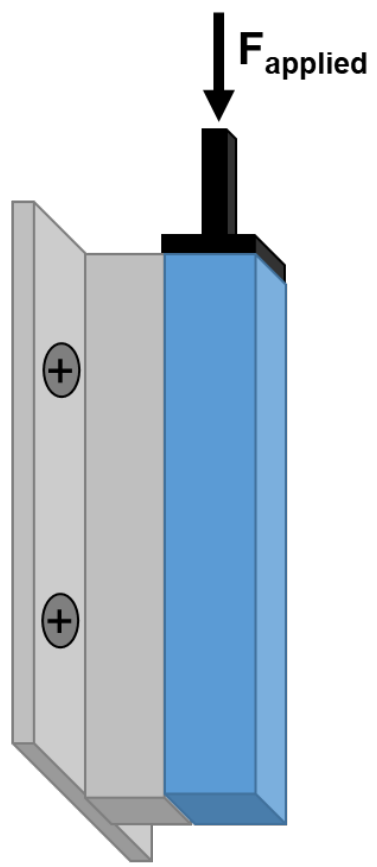

Figure 1. Loading configurations used for testing in the IAPT system: (a) tensile and (b) shear delamination modes. Ice is grown with a notch that can be loaded to lift the ice away in tension (as in a). For shear delamination, the flat front edge of the ice is pushed (as in $b$ ).

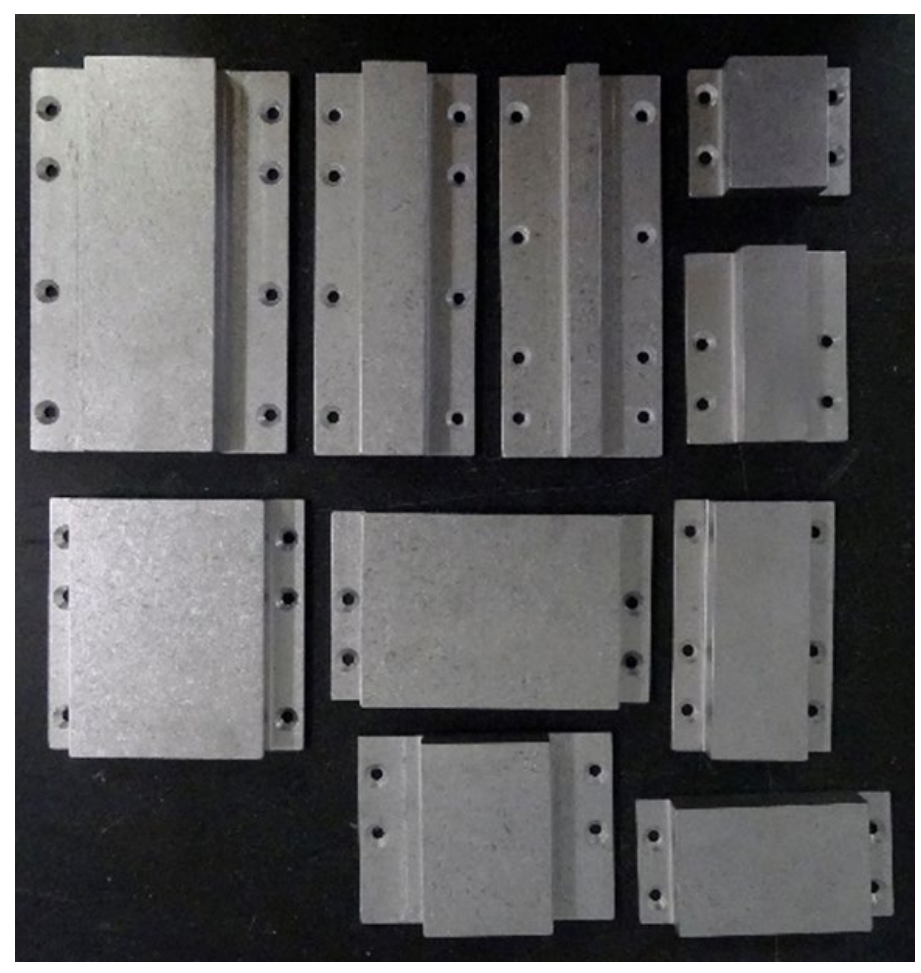

Figure 2. A snapshot of some of the different substrate sizes that can be used for ice growth and ice adhesion testing in the IAPT system at CRREL. All substrates shown are aluminum before polishing. Substrates can be fabricated from other machinable mateirals (e.g., titanium). 
Materials. The IAPT approach can accommodate a wide range of materials. Substrates can be made of any machinable material, including aluminum, Delrin, and MACOR; and coatings can be applied by almost any deposition method, including spray, dip, or brush methods, as long as the mounting holes and back of the substrate remain uncoated. In addition, fabrics and films can be affixed to an IAPT metal substrate, allowing testing of a planar section of a fabric or film. Table 1 describes the coatings, materials, and source information used in this report.

\begin{tabular}{|l|l||l||}
\hline \multicolumn{2}{|c||}{ Table 1. Details and source information for materials used in this study } \\
\hline $\begin{array}{c}\text { Coating Name } \\
\text { Used in This } \\
\text { Report }\end{array}$ & \multicolumn{1}{|c||}{$\begin{array}{c}\text { Coating/Substrate } \\
\text { Details }\end{array}$} & \multicolumn{1}{c||}{ Manufacturer/Supplier } \\
\hline \hline Standox & Standocryl 2K Klarlack/Aluminum & Standox-Wuppertal-Germany, PA, USA \\
\hline Aerodur & Aerodur/Aluminum & AzkoNobel Aerospace Coatings, IL, USA \\
\hline 3M 5490 & PTFE ${ }^{a}$ Film Tape 5490/Aluminum & $3 \mathrm{M}$, MN, USA \\
\hline Aluminum & Solid Aluminum & 6061, McMaster-Carr, CA, USA \\
\hline Titanium & Solid Titanium & Grade 5, McMaster-Carr, CA, USA \\
\hline Nanokote & Primoshield/Aluminum & Nanokote North America, Inc., TX, USA \\
\hline Super Ai & Nanomyte Super Ai/Aluminum & NEl Corporation, NJ, USA \\
\hline
\end{tabular}

${ }^{a}$ polytetrafluoroethylene

Substrate Preparation. This report focuses on the use of aluminum and titanium substrates, both with and without coatings and surface treatments. All substrates were polished with lapping films through p4000 grit papers, resulting in an average roughness of approximately $0.362 \mu \mathrm{m}$ as measured with an optical profilometer (Model ST400, Nanovea, CA, USA). Following the polishing process, substrates were rinsed with high-purity water, dried with ethanol, and stored in airtight bags with oxygen-absorbing packets (Oxy-Guard, Clariant, KY, USA) until used for coating or testing. At time of use, substrates were removed from the sealed bags, soaked in sulfuric acid ( $\mathrm{pH} \mathrm{1.5)} \mathrm{for} 5 \mathrm{~min}$, rinsed with high-purity water, and then dried by wiping with acetone or isopropanol. Substrates were then tested or had coatings applied within $30 \mathrm{~min}$ to limit the formation of aluminum oxide on the surfaces. All coatings were applied and cured according to manufacturer specifications.

Freshwater ice growth on substrates. Freshwater ice was grown on the substrates as outlined in Asenath-Smith, Hoch, and Erb (2020) and Asenath-Smith et al. (2020). In short, this method produces optically clear, bubble-free ice (Figure 4) and allows for ice growth directly on surfaces at a range of target temperatures. Moreover, this method enables IAPT testing as soon as ice growth is complete since there is no residual stress imposed by molds. All ice growth and adhesion tests reported herein were conducted at $-8^{\circ} \mathrm{C}$.

To ensure full engagement of the load head with the ice edge, a special notch and plastic film are used in the preparation of the substrates before ice growth (Figure 3; Asenath-Smith et al. 2021). 
The ice was grown off the surface to approximately $10 \mathrm{~mm}$ in thickness (Figure 4). After removal of the plastic and metal notch pieces, the flat ice edge is accessible for testing.

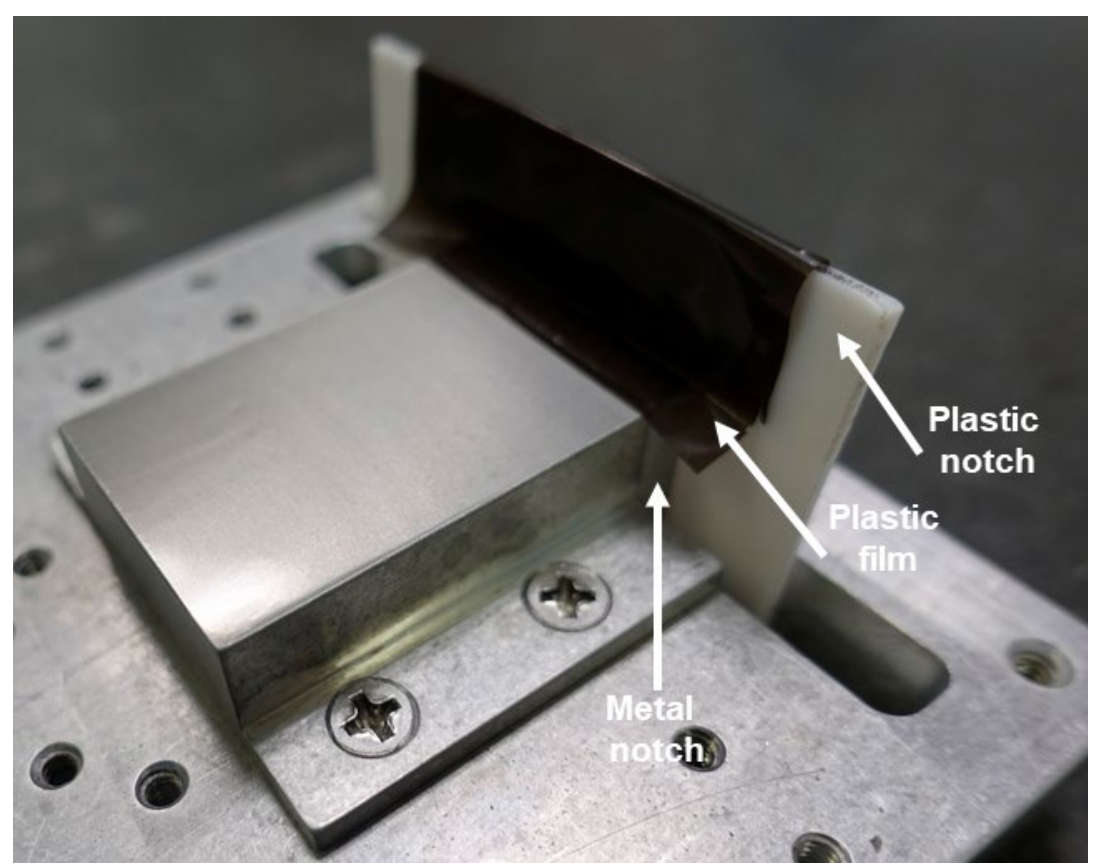

Figure 3. Substrate set up for ice growth, illustrating the metal and plastic notch pieces and the plastic film. All are used to ensure complete contact between the ice and load head and to facilitate the propagation of the delamination front down the ice-substrate interface for a completely adhesive delamination.

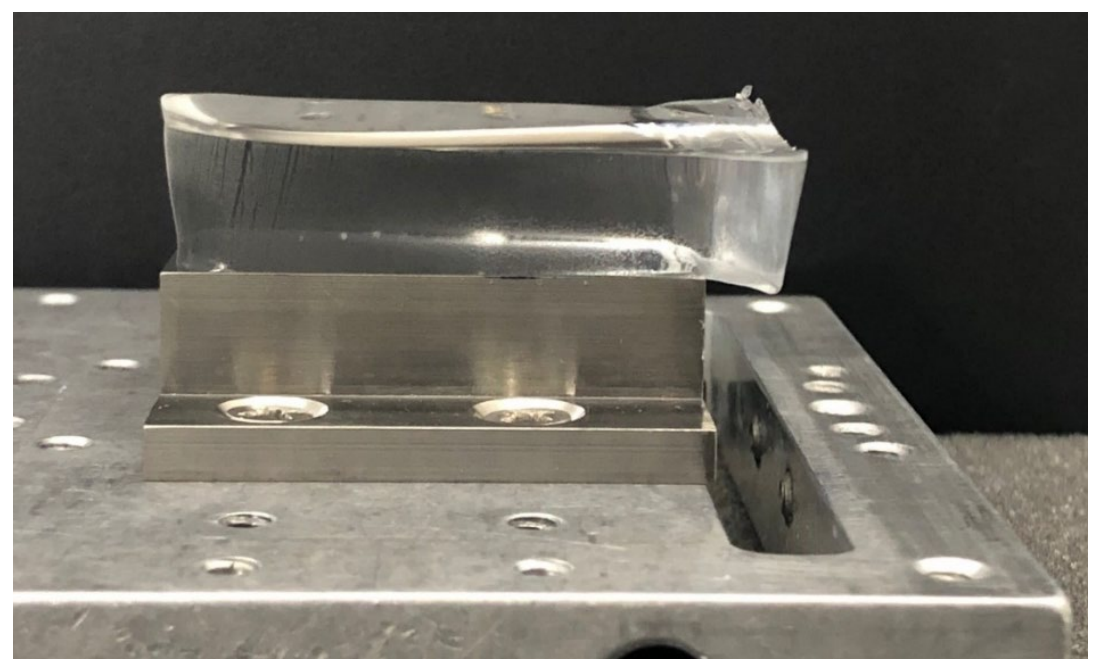

Figure 4. Side view of ice adhered to a titanium substrate and ready for testing. The notch pieces have been removed, revealing the flat ice edge that will be loaded during testing. 
RESULTS: Freshwater columnar ice was grown on seven different commercial materials at $-8^{\circ} \mathrm{C}$ over the course of approximately 1.5 hours. All tests were conducted within 30 minutes of ice growth being complete. Ice adhesion tests were performed in both tensile and shear delamination modes at $-8^{\circ} \mathrm{C}$ using the IAPT system in a universal load frame (Figure $5 a$ and $b$ ). In all tests, the delamination was purely adhesive; ice was completely removed from the substrates as a single piece without cohesive failure or remnants of ice on the surface after testing.

a)

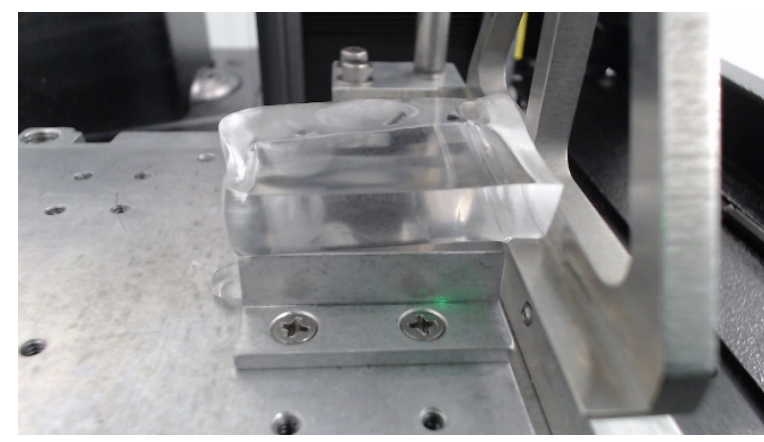

b)

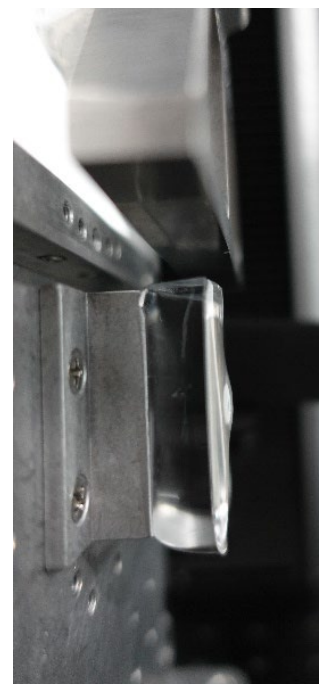

Figure 5. Specimens ready to test in the IAPT system using the tensile (a) and shear $(b)$ delamination modes. The ice sits atop the substrate, which is mounted ot the backplate. In (a), the edge of the load head is seen just under the edge of the ice to the right; in (b), the load head is seen directly above the ice edge. (See also Figure 1.)

Ice adhesion testing was performed on the materials with the IAPT in both tensile and shear delamination modes in replicates of at least five. Figures 6 and 7 and Table 2 summarize the results. The results show consistent values for the apparent ice adhesion strength with low standard deviations; all error values are nominally $10 \%$ or lower, demonstrating the robustness of this test to assess ice adhesion on a wide range of surfaces. Only the polished aluminum and titanium had error values greater than $10 \%$, which is not unexpected for a bare native material (Douglass and Palacios 2021).

In tensile delamination mode, the $3 \mathrm{M} 5490$ tape had the highest $\mathrm{IAS}_{\text {app }}$ of $32.3 \pm 1.4 \mathrm{kPa}$, while Super Ai had the lowest IAS $_{\text {app }}$ at $12.5 \pm 0.8 \mathrm{kPa}$. In shear, the Aerodur coating had the highest IAS $_{\text {app }}$ of $133.2 \pm 8.9 \mathrm{kPa}$, and the Super Ai coating was still the lowest at $28.9 \pm 2.4 \mathrm{kPa}$. It is not unexpected that the overall shear values are higher as compared the to the tensile values as the ice is pushed off the surface along the plane of the substrate. Lastly, the materials show different trends in IAS $_{\text {app }}$ between the two delamination modes, which is an observation that is still under investigation by researchers in the field of ice adhesion. 


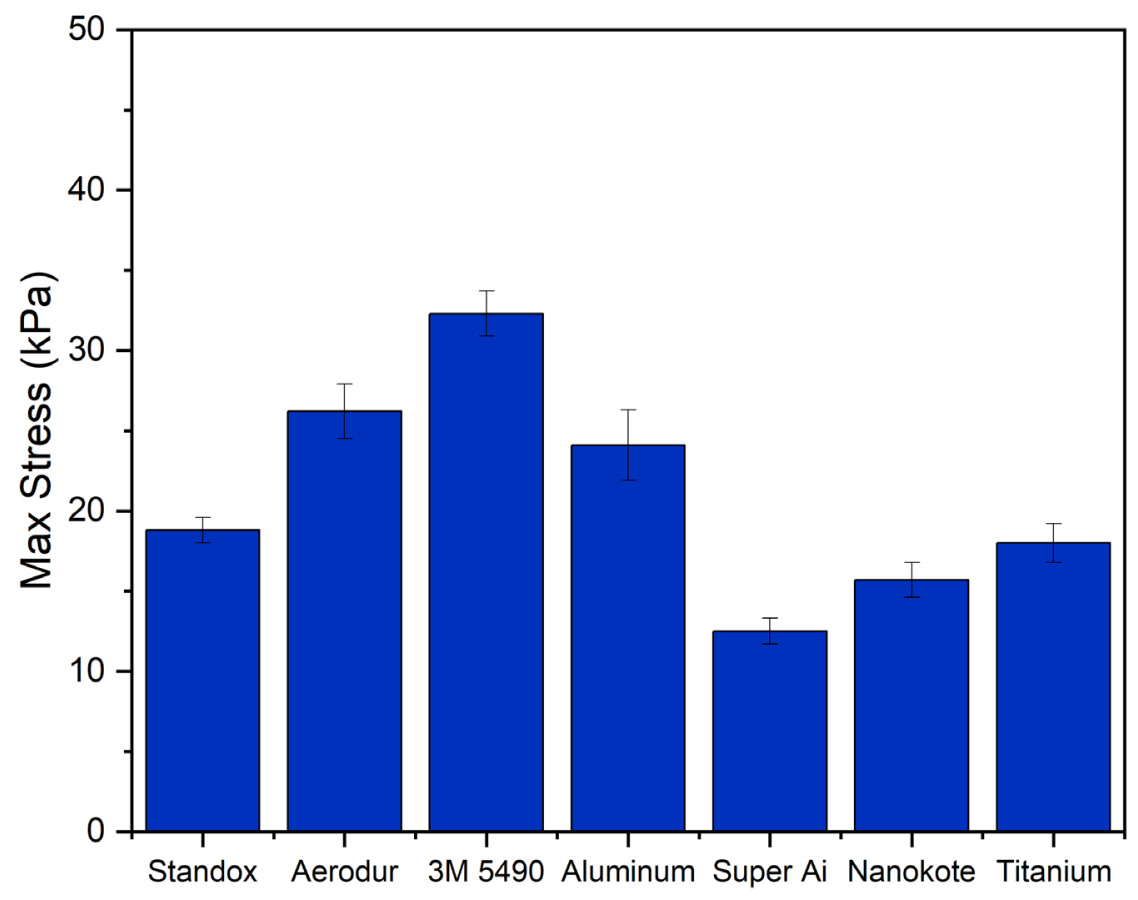

Figure 6. The apparent ice adhesion strength for commercial materials in a tensile delamination mode tested with the IAPT system in a tensile configuration at $-8^{\circ} \mathrm{C}$. Error bars represent the standard deviation of the average values. At least five replicates were used for each sample type.

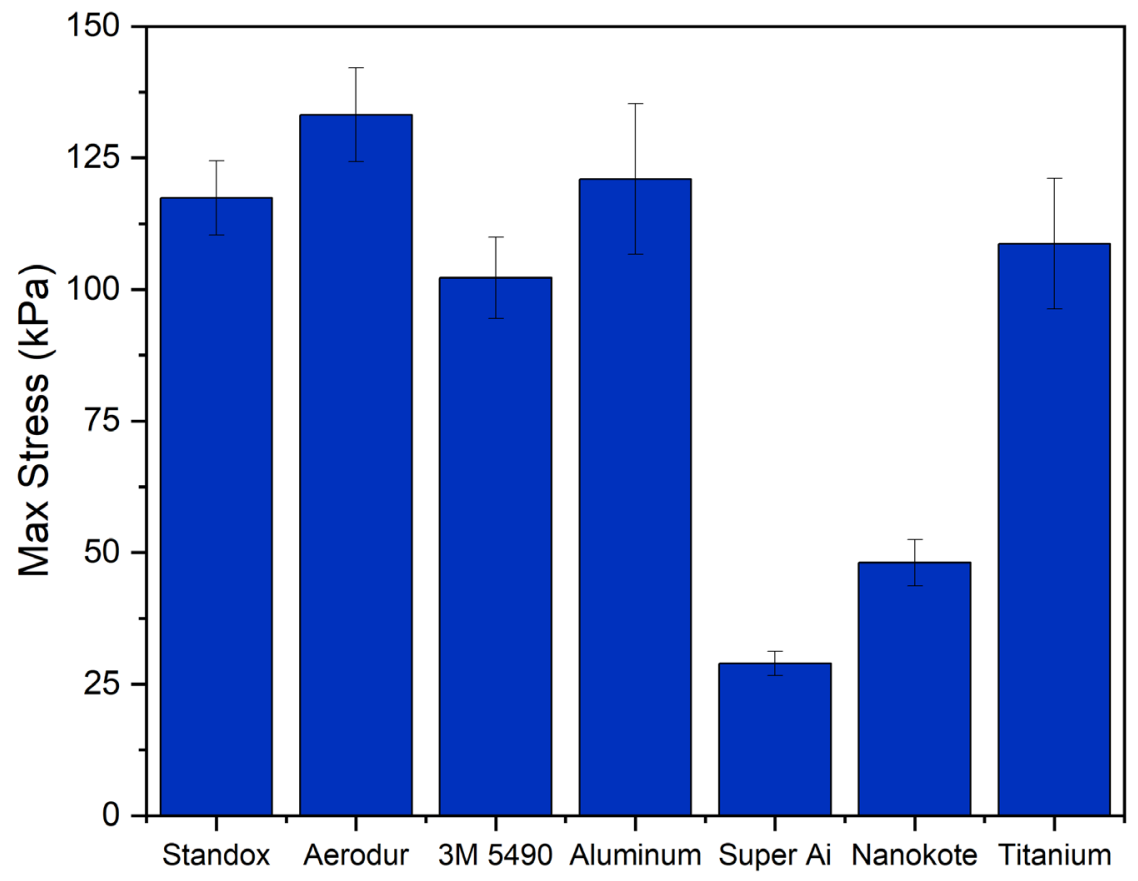

Figure 7. The apparent ice adhesion strength for commercial materials in a shear delamination mode tested using the IAPT system in a shear configuration at $-8^{\circ} \mathrm{C}$. Error bars represent the standard deviation of the average values. At least five replicates were used for each sample type. 


\begin{tabular}{|c|c|c|c|c|}
\hline $\begin{array}{l}\text { Test } \\
\text { Mode }\end{array}$ & $\begin{array}{l}\text { Coating/ } \\
\text { Substrate }\end{array}$ & $\begin{array}{l}\text { AIS } \\
(\mathrm{kPa})\end{array}$ & $\begin{array}{c}\text { Standard Deviation } \\
(\mathrm{kPa})\end{array}$ & $\begin{array}{l}\% \\
\text { Error }\end{array}$ \\
\hline \multirow[t]{7}{*}{ Tensile } & Standox & 18.8 & 0.8 & 4.4 \\
\hline & Aerodur & 26.2 & 1.7 & 6.7 \\
\hline & $3 M 5490$ & 32.3 & 1.4 & 4.2 \\
\hline & Aluminum & 24.1 & 2.2 & 9.0 \\
\hline & Titanium & 18.0 & 1.2 & 6.9 \\
\hline & Nanokote & 15.7 & 1.1 & 6.9 \\
\hline & Super Ai & 12.5 & 0.8 & 6.6 \\
\hline \multirow[t]{7}{*}{ Shear } & Standox & 117.4 & 7.0 & 6.0 \\
\hline & Aerodur & 133.2 & 8.9 & 6.7 \\
\hline & 3M 5490 & 102.2 & 7.7 & 7.5 \\
\hline & Aluminum & 121.0 & 14.3 & 11.8 \\
\hline & Titanium & 108.7 & 12.4 & 11.4 \\
\hline & Nanokote & 48.1 & 4.4 & 9.1 \\
\hline & Super Ai & 28.9 & 2.4 & 8.2 \\
\hline
\end{tabular}

CONCLUSION: Understanding the material properties that govern ice adhesion is a critical issue with slowed progress caused by the lack of formal standards for ice adhesion testing and analysis. Appropriate and comprehensive test methods must be developed that allow for varying-sized substrates and different ice types. Many ice adhesion tests, including the ZDCT and lap shear tests developed at CRREL, are widely used across the field; but most are capable of using only a single ice type and geometry and therefore provide only a limited assessment of materials in a single icing scenario.

In the immediate term, the IAPT presents a robust and versatile method for characterizing the ice adhesion properties of materials during research and development activities for a wide range of applications. The IAPT yields repeatable results on different material and coatings types and can be used with a variety of geometry substrates and ice types as needed for a given application. This report highlights the success of the IAPT, both as a present-day tool for material assessment and also as a longer-term solution to the development of formal standards for ice adhesion testing.

ADDITIONAL INFORMATION: This technical note was prepared by Ms. Alexis R. Lovell, STEM Student Employment Program intern; Mr. Garrett R. Hoch, research electrical engineer; Mr. Christopher J. Donnelly mechanical engineering technician; Mr. Jordan M. Hodge, engineering technician; Dr. Robert B. Haehnel, research mechanical engineer, and Dr. Emily Asenath-Smith, research materials engineer (Emily.Asenath-Smith@usace.army.mil), U.S. Army Engineer Research and Development Center, Cold Regions Research and Engineering Laboratory. This technical note should be cited as follows: 
Lovell, A. R., G. R. Hoch, C. J. Donnelly, J. M. Hodge, R. B. Haehnel, and E. AsenathSmith. 2021. Shear and Tensile Delamination of Ice from Surfaces: The Ice Adhesion Peel Test (IAPT). ERDC/CRREL TN-21-1. Hanover, NH: U.S. Army Engineer Research and Development Center. http://dx.doi.org/10.21079/11681/41781.

\section{REFERENCES}

Asenath-Smith, E, G. R. Hoch, and C. T. Erb. 2020. "Adhesion of Freshwater Columnar Ice to Material Surfaces by Crystallization from the Melt." Journal of Crystal Growth 535 (April):125563. https://doi.org/10.1016/j.jcrysgro.2020.125563.

Asenath-Smith, E., G. R. Hoch, D. A. Punt, C. Donnelly, and J. Hodge. 2020. Vertical Draw System and Method for Surface Adhesion of Crystalline Materials. U.S. Patent Application 16802490, filed 26 February 2020.

. 2021. System and Method for Testing Adhesion of Brittle Materials. U.S. Patent Application 17169203, filed 5 February 2021.

Douglass, R. G., and J. L. Palacios. 2021. "Effects of Strain Rate Variation on the Shear Adhesion Strength of Impact Ice." Cold Regions Science and Technology 181 (January): 103168. https://doi.org/10.1016/j.coldregions.2020.103168.

Ferrick, M. G., N. D. Mulherin, R. B. Haehnel, B. A. Coutermarsh, G. D. Durell, T. J. Tantillo, T. L. St. Clair, E. S. Weiser, R. J. Cano, T. M. Smith, and E. C. Martinez. 2006a. Double Lap Shear Testing of Coating-Modified Ice Adhesion to Space Shuttle Component Surfaces. ERDC-CRREL TR-06-21. Hanover, NH: U.S. Army Engineer Research and Development Center, Cold Regions Research and Engineering Laboratory. https:/hdl.handle.net/11681/5345.

- 2006b. Double Lap Shear Testing of Coating Modified Ice Adhesion to Liquid Oxygen Feed Line Bracket, Space Shuttle External Tank. ERDC-CRREL TR-06-11. Hanover, NH: U.S. Army Engineer Research and Development Center, Cold Regions Research and Engineering Laboratory. http://hdl.handle.net/11681/5335.

Haehnel, R. B., and N. D. Mulherin. 1998. "The Bond Strength of an Ice-Solid Interface Loaded in Shear." In Ice in Surface Waters: Proceedings of the 14th International Symposium on Ice, 27-31 July 1998, Potsdam, New York, 14:597-604. Rotterdam: Balkema Press.

Hakimian, A., S. Nazifi, and H. Ghasemi. 2020. "Metrology of Ice Adhesion.” In Ice Adhesion: Mechanism, Measurement, and Mitigation, edited by K. Mittal and C.-H. Choi, 217-236.

https://doi.org/10.1002/9781119640523.ch8.

NOTE: The contents of this technical note are not to be used for advertising, publication, or promotional purposes. Citation of trade names does not constitute an official endorsement or approval of the use of such products. 